\title{
General Psychiatry Effects of ketamine in electroconvulsive therapy for major depressive disorder: meta-analysis of randomised controlled trials
}

\author{
Xiao-Mei Li (D , ${ }^{1}$ Zhan-Ming Shi, ${ }^{2}$ Pei-Jia Wang, ${ }^{1}$ Hua $\mathrm{Hu}^{1}$
}

To cite: Li X-M, Shi Z-M, Wang P-J, et al. Effects of ketamine in electroconvulsive therapy for major depressive disorder: meta-analysis of randomised controlled trials. General Psychiatry 2020;33:e100117. doi:10.1136/ gpsych-2019-100117

- Additional material is published online only. To view, please visit the journal online (http://dx.doi.org/10.1136/ gpsych-2019-100117).

Received 01 August 2019 Revised 30 March 2020 Accepted 16 April 2020

\section{Check for updates}

(C) Author(s) (or their employer(s)) 2020. Re-use permitted under CC BY-NC. No commercial re-use. See rights and permissions. Published by BMJ.

${ }^{1}$ Department of Psychiatry, The First Affiliated Hospital of Chongqing Medical University, Chongqing, China

${ }^{2}$ Department of Psychiatry, Chongqing Jiangbei Mental Health Center, Chongqing, China

Correspondence to

Dr Hua Hu;

huhuateam@hotmail.com

\section{ABSTRACT}

Background The use of ketamine in electroconvulsive therapy (ECT) has been examined in the treatment of major depressive disorder (MDD); however, there has been no systematic review and meta-analysis of related randomised controlled trials (RCTs).

Aim To examine the efficacy and safety of ketamine augmentation of ECT in MDD treatment.

Methods Two reviewers searched Chinese (China National Knowledge Infrastructure and Wanfang) and English (PubMed, PsycINF0, Embase and Cochrane Library) databases from their inception to 23 July 2019. The included studies' bias risk was evaluated using the Cochrane risk of bias assessment tool. The primary outcome of this metaanalysis was improved depressive symptoms at day 1 after a single ECT treatment session. Data were pooled to calculate the standardised mean difference and risk ratio with their 95\% Cls using RevMan V.5.3. We used the Grading of Recommendations, Assessment, Development and Evaluation (GRADE) approach to assess the whole quality of evidence.

Results Four RCTs $(n=239)$ compared ketamine alone or ketamine plus propofol $(n=149)$ versus propofol alone $(n=90)$ in patients with MDD who underwent a single ECT session. Three RCTs were considered as unclear risk with respect to random sequence generation using the Cochrane risk of bias. Compared with propofol alone, ketamine alone and the combination of ketamine and propofol had greater efficacy in the treatment of depressive symptoms at days 1, 3 and 7 after a single ECT session. Moreover, compared with propofol alone, ketamine alone and the combination of ketamine and propofol were significantly associated with increased seizure duration and seizure energy index. Compared with propofol, ketamine alone was significantly associated with increased opening-eye time. Based on the GRADE approach, the evidence level of primary and secondary outcomes ranged from very low $(26.7 \%, 4 / 15)$ to 'low' (73.3\%, 11/15).

Conclusion Compared with propofol, there were very low or low evidence levels showing that ketamine alone and the combination of ketamine and propofol appeared to rapidly improve depressive symptoms of patients with MDD undergoing a single ECT session. There is a need for highquality RCTs.

\section{INTRODUCTION}

Electroconvulsive therapy (ECT), which is also known as electroshock therapy, is an effective treatment procedure for major mental disorders, including schizophrenia, bipolar disorder and major depressive disorder (MDD). ${ }^{1}$ General anaesthesia renders unconscious patients free from muscle paralysis and/or even recall and is wildly applied to all ECT procedures in clinical practice. ${ }^{2}$ Duration of seizure activity, recovery and haemodynamic parameters could be affected by the choice of anaesthetic agent for ECT. Thus, there is a need to determine the optimal choice of anaesthetic agent for ECT from several agents, including ketamine, propofol, etomidate, sevoflurane, ethohexital and thiopental. ${ }^{3}$

Ketamine is an N-methyl-D-aspartate (NMDA) antagonist with a rapid antidepressant effect. ${ }^{4}$ Despite its risk of potential adverse drug reactions (ADRs), ${ }^{6}$ increasing randomised controlled trials (RCTs) have reported that ketamine was significantly superior to placebo in reducing depressive symptoms in patients with unipolar or bipolar depression. ${ }^{7-11}$ Ketamine is often used in ECT and can cause a favourable seizure outcome by inducing action and increasing seizure duration. ${ }^{12}{ }^{13}$ However, ketamine could cause delayed recovery, as well as induce transitory psychotic episodes and cardiotoxicity. ${ }^{14}$

Given the correlation of propofol with reasonable haemodynamic response to ECT, it has become increasingly popular in ECT anaesthesia. ${ }^{15}$ However, propofol has limitations with respect to reduced seizure duration and increased seizure threshold. ${ }^{16}$ The combination of ketamine and propofol has been successfully employed for various anaesthetic procedures. ${ }^{2}$ This could be attributed to the following: (1) ketamine can mitigate propofol-related hypotension and (2) 
propofol can mitigate ketamine-induced recovery agitation and vomiting. Thus, the use of the combination of propofol and ketamine has theoretical benefits, including obviating the need for opioid coadministration and minimising the propofol dose.

There have been several RCTs ${ }^{12}{ }^{17-19}$ on the use of ketamine alone or ketamine plus propofol in a single ECT treatment session for patients with MDD; however, they have reported inconsistent findings. A recent metaanalysis of seventeen RCTs found that ketamine alone did not increase the antidepressant ECT effect; moreover, ketamine combined with other anaesthetics has a shortterm advantage with respect to improvement of depressive symptoms at the early ECT stages ${ }^{20}$. These findings are consistent with those of another meta-analysis. ${ }^{21}$ However, this meta-analysis ${ }^{20}$ did not include RCTs with a single ECT session. ${ }^{12}{ }^{17-19}$ Notably, there has been no systematic review or meta-analysis exclusively investigating the effectiveness and safety of adjunctive ketamine with single ECT treatment in patients with MDD. Thus, we aimed to perform a meta-analysis to examine the effectiveness and safety of ketamine alone and that of ketamine combined with propofol in patients with MDD undergoing a single ECT treatment.

\section{METHODS}

\section{Search strategy}

This meta-analysis was conducted in accordance with the recommendations of the Preferred Reporting Items for Systematic Reviews and Meta-analyses (PRISMA) checklist. ${ }^{22}$ As recommended by recent meta-analyses, ${ }^{2324}$ English (PubMed, Embase, PsycINFO and Cochrane Library databases) and Chinese (China National Knowledge Infrastructure and Wanfang database) databases were independently searched by two reviewers (X-ML and Z-MS) on the same day to retrieve studies published in Chinese and English journals from their inception to 23 July 2019 using the following search strategy: ('depression' (MeSH) OR depressive OR depressed OR depression) AND ('electroconvulsive therapy' (MeSH) OR ECT OR electroconvulsive therapy) AND (NMDA OR ketamine OR glutamat*OR N-methyl-D-aspartic acid) AND ('propofol'(MeSH) OR propofol). Reference lists of the retrieved trials,${ }^{2025-28}$ relevant reviews and metaanalyses were manually searched to obtain missing RCTs.

\section{Eligibility criteria}

The inclusion criteria were as per the following PICOS acronym: participants: patients with MDD diagnosed using any criteria; intervention versus comparison: (1) ketamine alone versus propofol alone in ECT and (2) ketamine + propofol versus propofol alone in ECT; outcomes: the primary outcome was the improvement of depressive symptoms at day 1 after a single ECT treatment measured using standardised rating scales (including the Montgomery and Asberg Depression Rating Scale ${ }^{29} 30$ or the Hamilton Depression Rating Scale (HAMD)). ${ }^{31}{ }^{32}$ As recommended by a previous meta-analysis, HAMD was preferred to other scales in studies using multiple rating scales. ${ }^{27}$ Key secondary outcomes were (1) improvement of depressive symptom at days 3 and 7 after a single ECT session; (2) the improvement of suicide ideation; (3) seizure duration and recovery times, and (4) ADRs. Study design: only RCT with a single ECT session. Studies with multiple ECT sessions ( $\geq 2$ times) were excluded. ${ }^{33-46}$ Observational studies, conference articles, case report/ series and meta-analyses and systematic reviews were excluded. Moreover, multiple-intervention studies, including ECT combined with acupuncture or Chinese herbal medicine, were excluded.

\section{Data extraction}

Two reviewers (X-ML and Z-MS) independently extracted and checked data. During the data extraction process, disagreements were resolved through discussion and consensus or with the involvement of a senior reviewer $(\mathrm{HH})$. Study authors were contacted by email or telephone to obtain more meta-analysable data. The WebPlotDigitizer V.4.1 (https:/ /automeris.io/WebPlotDigitizer/) was used to extract data from figures and/or graphs of the included RCTs as described by a recent metaanalysis. ${ }^{47}$ Missing SDs were calculated from test statistics or using the mean (SD) of the remaining studies. ${ }^{48}$ Three $\mathrm{RCTs}^{121718}$ with three treatment arms compared propofol with ketamine alone and with ketamine combined with propofol, separately. We included propofol arms twice in the aforementioned respective analyses and used half of the number of patients in the propofol arms. ${ }^{49}$

\section{Statistical methods}

Two reviewers (X-ML and Z-MS) independently analysed data of the included RCTs using the Review Manager V.5.3 (http://www.cochrane.org) based on the PRISMA statement. $^{50}$ Standardised mean differences (SMDs) with their 95\% CIs and risk ratios (RRs) with its 95\% CIs were calculated. SMD values over $0.8,0.5-0.8$ and $0.2-0.5$ represented large, medium and small effect sizes, respectively. ${ }^{51}$ All meta-analysable outcomes were pooled using a random effects model ${ }^{52}$ The $Q$ statistics and $\mathrm{I}^{2}$ were used to assess between-study heterogeneity with a $\mathrm{p}$ value of $<0.1$ in $Q$ test and $\mathrm{I}^{2}$ of $\geq 50 \%$ indicating significant heterogeneity. ${ }^{53}$ In case of a $\mathrm{p}$ value of $<0.1$ or $\mathrm{I}^{2}$ of $\geq 50 \%$ for the improvement of depressive symptoms at day 1 after a single ECT session, a sensitive analysis was conducted to examine the robustness of meta-analytic results after excluding an outlying study (SMD $\leq-3.50) .{ }^{17}$ Funnel plots and Egger's test ${ }^{54}$ were applied to investigate the possibility of publication bias. All meta-analysable primary and secondary outcomes were considered significant with alpha set at 0.05 (two-sided).

\section{Quality assessment of each included study}

Two reviewers (X-ML and Z-MS) independently conducted quality assessment of each included study using the Cochrane risk of bias ${ }^{55}$ and the Jadad scale 
A total of 209 articles published before July 23, 2019 were identified from PubMed ( $=30)$, Embase $(n=95)$, PsycINFO $(n=26)$, Cochrane Library $(n=30)$, $\operatorname{CNKI}(n=10)$, and Wanfang database $(n=18)$ using the following search terms (in the title or abstract): ('depression' [MeSH] OR depressive OR depressed OR depression) AND ('electroconvulsive therapy' [MeSH] OR ECT OR electroconvulsive therapy) AND (NMDA OR ketamine OR glutamat*OR Nmethyl-D-aspartic acid) AND ('propofol' [MeSH] OR propofol)



The titles or abstracts of the $\mathbf{1 5 1}$ articles were screened

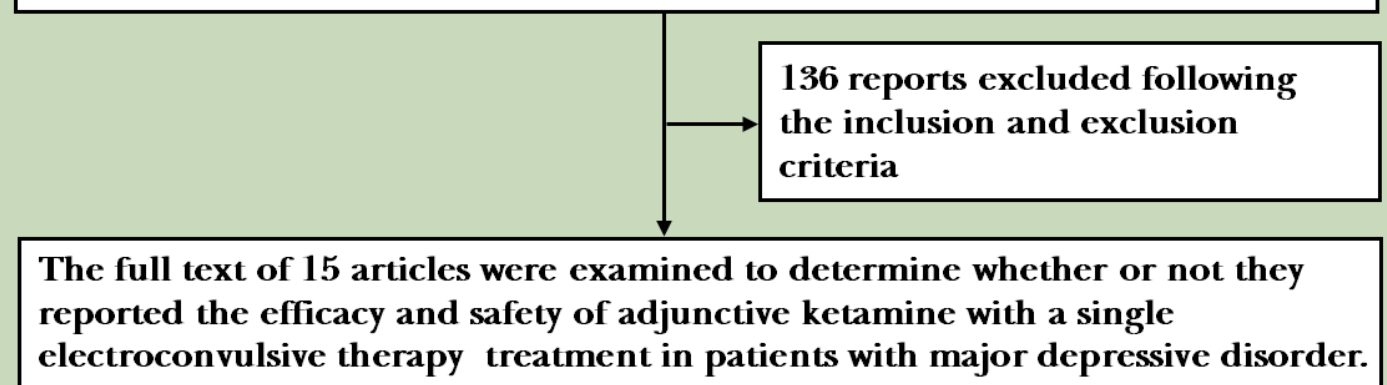
reported the efficacy and safety of adjunctive ketamine with a single electroconvulsive therapy treatment in patients with major depressive disorder.

\begin{tabular}{|l|}
\hline Full-text articles excluded $(n=11):$ \\
- S-ketamine study $(n=1)$ \\
- Multiple electroconvulsive \\
therapy session $(n=7)$ \\
- Case report $(n=1)$ \\
- Conference articles $(n=2)$
\end{tabular}

Finally, 4 randomised controlled trials were included in qualitative synthesis.

Figure 1 Flowchart of the literature screening.

(range $=0-5) .{ }^{56}$ The Grading of Recommendations, Assessment, Development and Evaluation (GRADE) system $^{57} 58$ was applied to examine the overall evidence levels for all meta-analytical outcomes.

\section{RESULTS}

\section{Search results}

We identified 209 hits from the aforementioned databases (figure 1); among them, 58 duplicates were removed. Subsequently, 151 articles were screened for titles and abstracts with 136 reports being excluded according to the inclusion and exclusion criteria. Next, 15 full texts were examined with 11 articles being excluded as follows: an S-ketamine study (one trial), multiple ECT sessions (seven trials), a case report (one trial) and conference articles (two trials). Finally, four RCTs with a single ECT session were included in this meta-analysis. ${ }^{12} 17-19$

\section{Study characteristics}

Four RCTs ( $\mathrm{n}=239)$, which compared ketamine alone or ketamine plus propofol $(\mathrm{n}=149)$ versus propofol alone $(\mathrm{n}=90)$, were included.

\section{Ketamine versus propofol}

Four RCTs $(\mathrm{n}=178)$ compared ketamine alone $(\mathrm{n}=88)$ versus propofol $(\mathrm{n}=90)$. The mean age was 48 (range: 41-55) years in two studies with available data; moreover, $44.8 \%$ of the participants (range: $36.7 \%-51.9 \%$ ) in three studies with available data were men. None of the studies reported the mean duration of illness (table 1 ).

\section{Ketamin+propofol versus propofol}

Three RCTs ( $\mathrm{n}=122$ ) compared ketamine+propofol ( $\mathrm{n}$ $=61)$ with propofol $(\mathrm{n}=61)$. Only one study with available data reported the mean age ( 56.5 years); moreover, $39.8 \%$ of the participants (range: $36.7 \%-42.9 \%$ ) were 


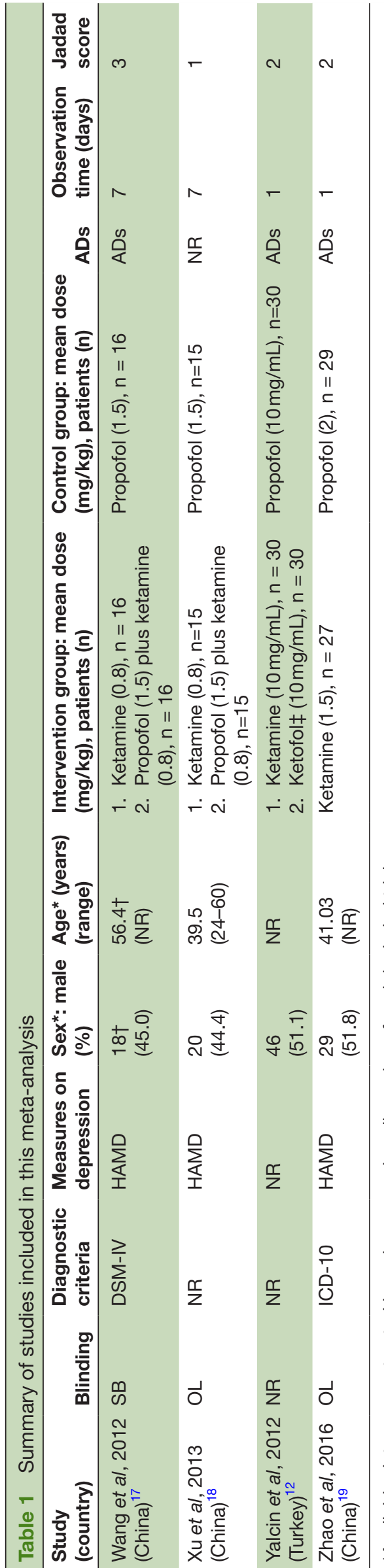

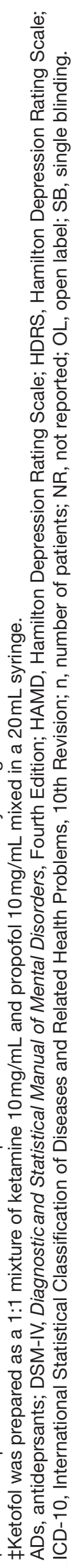

men in two studies with available data. None of the studies reported the mean illness duration (table 1 ).

\section{Quality assessment}

In the Cochrane risk of bias (online supplementary figure $1)$, three RCTs $(75 \%, 3 / 4)$ were judged as unclear risk with respect to random sequence generation. The Jadad scores ranged from 1 to 3 (mean $=2.0)$ with only one RCT (25\%) being considered as high quality (table 1). Online supplementary table 1 summarises the overall evidence level for all meta-analytic primary and secondary measures, which ranges from very low $(26.7 \%, 4 / 15)$ to 'low' $(73.3 \%, 11 / 15)$.

\section{Primary outcomes}

Ketamine alone was superior to propofol with regard to the improvement of depressive symptoms at days 1 (SMD: $-2.37,95 \%$ CI -4.50 to $-0.25, \mathrm{I}^{2}=90 \%, \mathrm{p}=0.03$; large effect size), 3 (SMD: $-3.94,95 \%$ CI -5.08 to $-2.79, \mathrm{I}^{2}=0 \%$, $\mathrm{p}<0.001$; large effect size) and 7 (SMD: $-2.98,95 \%$ CI -3.94 to $-2.01, \mathrm{I}^{2}=0 \%, \mathrm{p}<0.001$; large effect size) after a single ECT session (figure 2). After excluding an outlying study $(\mathrm{SMD} \leq-3.59),{ }^{17}$ the significant difference disappeared (SMD: $-1.88,95 \% \mathrm{CI}-4.49$ to $0.74, \mathrm{I}^{2}=92 \%$, $\mathrm{p}=$ $0.16)$.

Similarly, the combination of ketamine and propofol was superior to propofol with regard to the improvement of depressive symptoms at days 1 (SMD: -2.99 , 95\% CI -3.94 to $-2.04, \mathrm{I}^{2}=0 \%, \mathrm{p}<0.001$; large effect size), 3 (SMD: $-3.87,95 \%$ CI -4.97 to $-2.77, \mathrm{I}^{2}=0 \%, \mathrm{p}<0.001$; large effect size) and 7 (SMD: $-3.08,95 \% \mathrm{CI}-4.04$ to -2.11 , $\mathrm{I}^{2}=$ $0 \%, \mathrm{p}<0.001$; large effect size) after a single ECT session (figure 3). None of the studies examined the relationship between ketamine used in ECT and suicide ideation.

\section{Secondary outcomes}

As shown in table 2, ketamine alone was significantly associated with increased seizure duration (SMD: -2.11, $95 \%$ CI 1.54 to $2.67, \mathrm{I}^{2}=0 \%, \mathrm{p}<0.001$; large effect size), seizure energy index (SMD: $-1.74,95 \%$ CI 0.97 to 2.51 , $\mathrm{I}^{2}=0 \%, \mathrm{p}<0.001$; large effect size) and eye-opening time (SMD: 2.73 , 95\% CI 1.53 to $3.94, \mathrm{I}^{2}=64 \%$, $\mathrm{p}<0.001$; large effect size) compared with propofol.

Similarly, ketamine combined with propofol was significantly associated with increased seizure duration (SMD: $-2.11,95 \%$ CI 0.55 to $3.67, \mathrm{I}^{2}=84 \%, \mathrm{p}=0.008$; large effect size) and seizure energy index (SMD: $-1.71,95 \%$ CI 0.95 to $2.47, \mathrm{I}^{2}=0 \%, \mathrm{p}<0.001$; large effect size) compared with propofol. There was no group difference in the eyeopening time (SMD: $1.78,95 \% \mathrm{CI}-0.31$ to $3.86, \mathrm{I}^{2}=88 \%$, $\mathrm{p}=0.09$; large effect size).

There was no significant difference regarding hypertension between propofol and ketamine alone $(\mathrm{p}=0.51)$ and between propofol and ketamine combined with propofol $(p=0.65)$. There was no group difference regarding nausea and vomiting between ketamine and propofol alone $(\mathrm{p}=0.78)$ (table 2). 


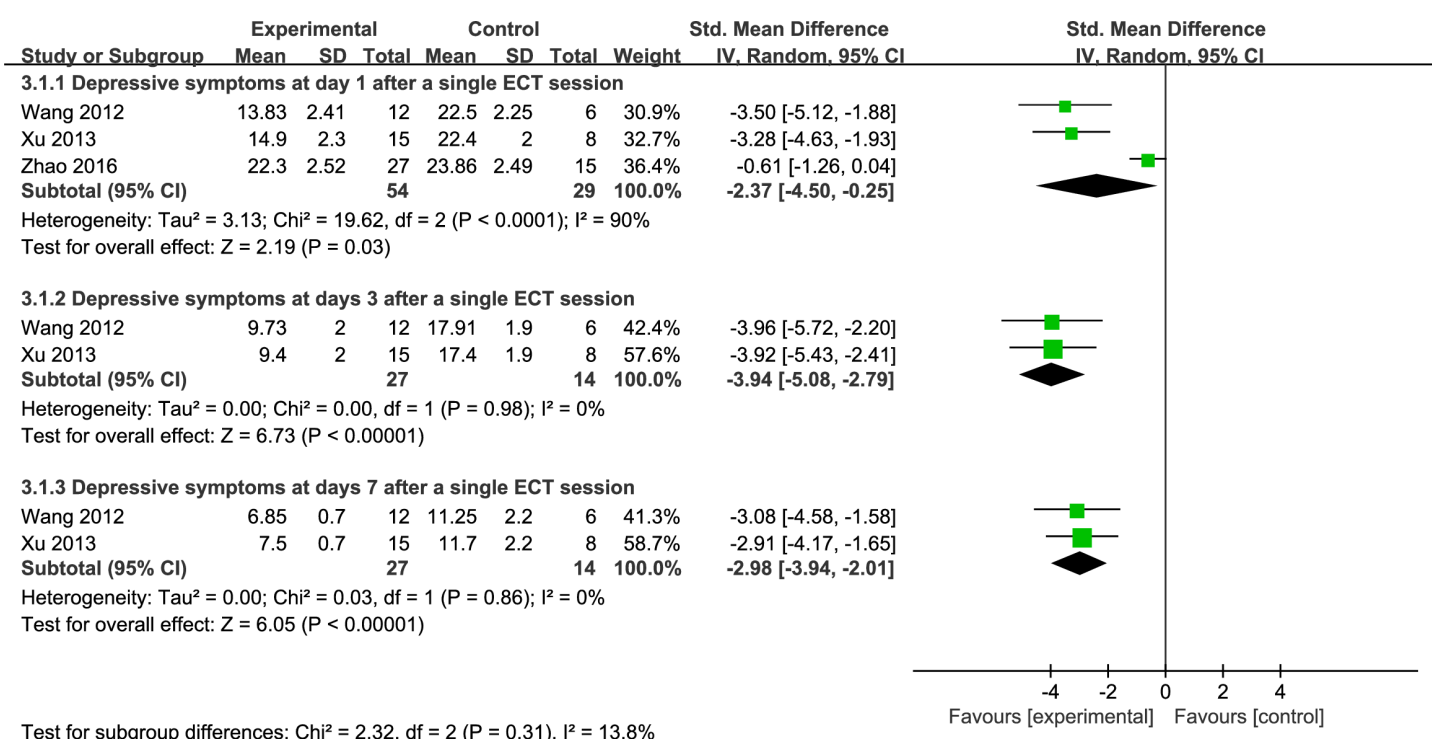

Figure 2 The ketamine group versus the propofol group: forest plot for depressive symptoms at days 1,3 and 7 after a single electroconvulsive therapy session.

\section{Publication bias}

Publication bias was not evaluated for all outcomes because a minimum of 10 RCTs are needed to perform funnel plot or Egger's test. ${ }^{59}$

\section{DISCUSSION}

\section{Main findings}

This is the first meta-analysis to examine the effectiveness and safety of ketamine alone or ketamine combined with propofol in patients with MDD undergoing a single ECT session. Ketamine alone and ketamine combined with propofol were more efficacious than propofol alone as an ECT anaesthesia in treating depressive symptoms at days 1,3 and 7 after a single ECT session with large effect size. ${ }^{51}$ However, the significant superiority of ketamine to propofol alone in improving depressive symptoms was driven by an outlying study. ${ }^{17}$ Compared with propofol, ketamine alone and the combination of ketamine and propofol significantly increased the seizure duration and seizure energy index. Furthermore, ketamine alone, but not ketamine combined with propofol, could significantly increase opening-eye time compared with propofol. However, a recent study found that ketamine as an anaesthetic did not enhance the antidepressant effects of six ECT treatments. ${ }^{45}$

\section{Limitations}

This study has several limitations. Firstly, the number of included RCTs and sample size of each included RCT were relatively small, which impeded more comprehensive analyses, including subgroup and meta-regression analyses. Secondly, the significant heterogeneity in the meta-analytic findings for the primary outcome could be partly attributed to each included study with differences

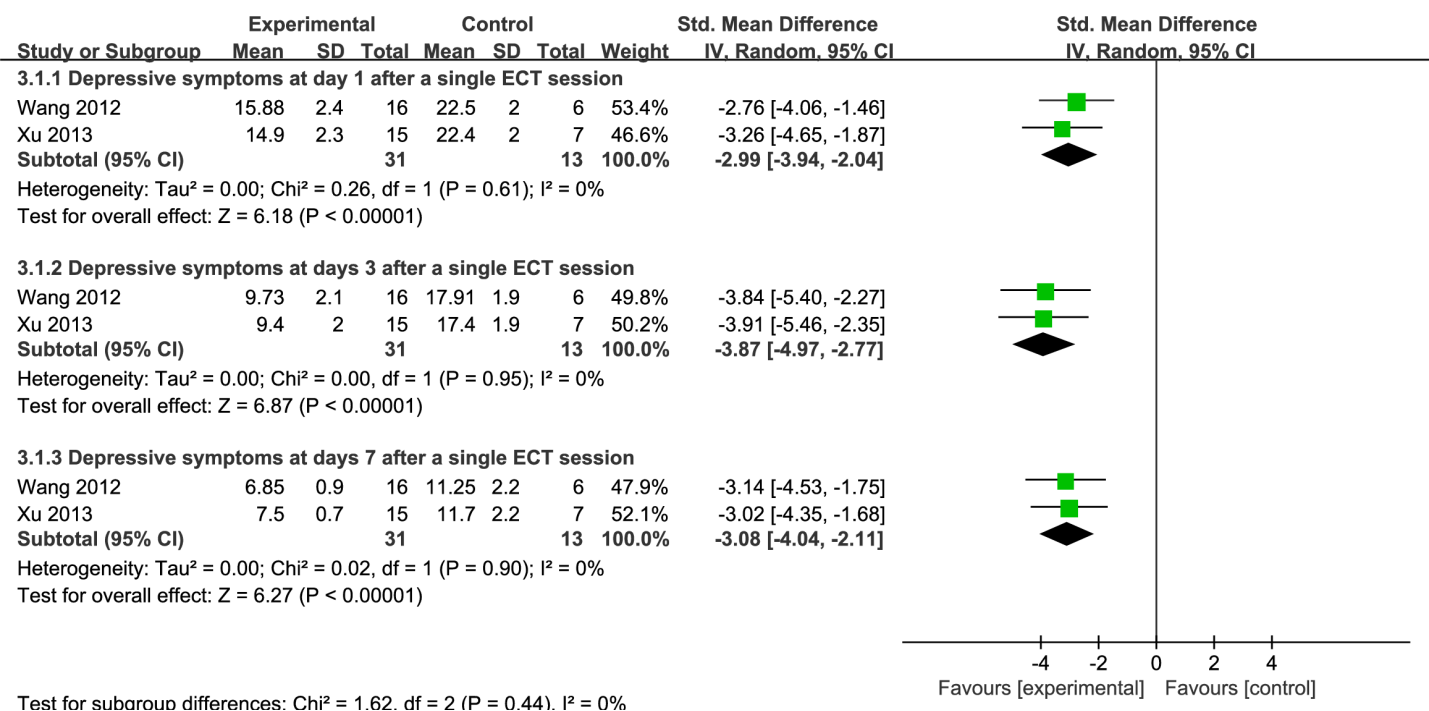

Figure 3 Combination of the ketamine and propofol group versus the propofol group: forest plot for depressive symptoms at days 1,3 and 7 after a single electroconvulsive therapy session. 


\begin{tabular}{|c|c|c|c|c|}
\hline Secondary outcomes & $\begin{array}{l}\text { Subjects (active } \\
\text { treatment arms) }\end{array}$ & SMDs or RRs $(95 \% \mathrm{Cl})$ & $I^{2}(\%)$ & $P$ value \\
\hline \multicolumn{5}{|l|}{ Ketamine versus propofol } \\
\hline Seizure duration (s) & $86(3)$ & $-2.11(1.54$ to 2.67$)$ & 0 & $<0.001$ \\
\hline Seizure energy index (uv2) & $41(2)$ & $-1.74(0.97$ to 2.51$)$ & 0 & $<0.001$ \\
\hline Open eyes (min) & $68(2)$ & $2.73(1.53$ to 3.94$)$ & 64 & $<0.001$ \\
\hline Hypertension & $92(3)$ & 1.31 (0.58 to 2.93$)$ & 0 & 0.51 \\
\hline Nausea and vomiting & $92(3)$ & $1.19(0.34$ to 4.20$)$ & 0 & 0.78 \\
\hline \multicolumn{5}{|c|}{ Ketamine plus propofol versus propofol } \\
\hline Seizure duration (s) & $89(3)$ & $-2.11(0.55$ to 3.67$)$ & 84 & 0.008 \\
\hline Seizure energy index (uv2) & $44(2)$ & $-1.71(0.95$ to 2.47$)$ & 0 & $<0.001$ \\
\hline Open eyes (min) & $67(2)$ & $1.78(-0.31$ to 3.86$)$ & 88 & 0.09 \\
\hline Hypertension & $91(3)$ & $0.81(0.33$ to 2.00$)$ & 0 & 0.65 \\
\hline
\end{tabular}

Boldfaced values: data was considered to have significant differences when $p<0.05$.

$\mathrm{RR}$, risk ratio; SMD, standardised mean difference.

in methodological characteristics, including the dosage of propofol and ketamine, electrode placements and patient property. Further, future studies should compare between single and multiple ECT sessions for MDD. Finally, none of the RCTs reported randomisation methods with a specific description as measured by the Cochrane risk of bias; moreover, three RCTs $(75 \%, 3 / 4)$ were rated as low quality as measured by the Jadad scale. Furthermore, quality of evidence for all meta-analytic outcomes was considered as 'very low' or low according to the GRADE approach. However, as suggested by Guyatt et al., ${ }^{60}$ low-quality evidence could still lead to strong recommendations.

\section{Implications}

We found that ECT-treated patients with MDD receiving ketamine plus propofol or ketamine alone had more significant improvements in depressive symptoms compared with patients receiving propofol alone. This suggests that ketamine alone or the combination of ketamine and propofol as an ECT anaesthesia has an early and rapid antidepressant effect superior to that of propofol anaesthesia, which was consistent with the findings of previous meta-analyses indicating that ketamine has rapid antidepressant effects. ${ }^{9}$

Two previous meta-analyse ${ }^{2021}$ reported that ketamine used in ECT did not reduce the depressive symptoms at the end of the treatment; however, it could accelerate the antidepressive effects in depressive patients undergoing ECT. Thus, ketamine use in ECT has considerable clinical significance because the delayed onset of antidepressant effects is closely associated with prolonged severe morbidity suicide risk. ${ }^{61}$ However, none of the included RCTs assessed the antisuicidal effects of ketamine used in ECT. The incidence of hypertension was similar in the ketamine group and ketamine combined with the propofol group compared with the propofol group.
Thus, the use of ketamine and ketamine combined with propofol is safe and tolerable.

As expected, there were significant difference regarding the seizure activity duration and the seizure energy index between propofol and ketamine alone, and ketamine combined with propofol. Interestingly, the combination of ketamine and propofol group was not associated with longer mean eye-opening time compared with the propofol group. Thus, the use of ketamine plus propofol as an ECT anaesthesia might be advantageous for analgesia and haemodynamic stability. ${ }^{12}$ Notably, ketaminerelated nauseant and psychomimetic effects could be counterbalanced by the sedative and antiemetic effects of propofol. Given the potential balance of effects, the combination of ketamine and propofol as an ECT anaesthesia is superior to either agent alone. ${ }^{12}$

\section{CONCLUSION}

According to very low or low evidence level, compared with propofol alone, ketamine alone and the combination of ketamine and propofol have an advantage in rapidly improving depressive symptoms of patients with MDD undergoing a single ECT session. Due to significant heterogeneity and small sample size, high-quality RCTs are required to confirm and extend these findings.

Acknowledgements We thank Wei Zheng, MD, PhD, Department of Psychiatry, the Affiliated Brain Hospital of Guangzhou Medical University (Guangzhou Huiai Hospital), Guangzhou, China, for his edits to this work.

Contributors X-ML and Z-MS selected the studies, conducted the statistical analysis, extracted the data and wrote the first draft. $\mathrm{HH}$ reviewed all the data and helped mediate disagreements. HH and P-JW made critical revisions. All the authors contributed to the interpretation of data and approved the final manuscript.

Funding The authors have not declared a specific grant for this research from any funding agency in the public, commercial or not-for-profit sectors.

Competing interests None declared.

Patient consent for publication Not required. 
Provenance and peer review Not commissioned; externally peer reviewed.

Data availability statement № additional unpublished data are sharing.

Open access This is an open access article distributed in accordance with the Creative Commons Attribution Non Commercial (CC BY-NC 4.0) license, which permits others to distribute, remix, adapt, build upon this work non-commercially, and license their derivative works on different terms, provided the original work is properly cited, appropriate credit is given, any changes made indicated, and the use is non-commercial. See: http://creativecommons.org/licenses/by-nc/4.0/.

\section{ORCID iD}

Xiao-Mei Li http://orcid.org/0000-0003-3806-3077

\section{REFERENCES}

1 Petrides G, Fink M, Husain MM, et al. Ect remission rates in psychotic versus nonpsychotic depressed patients: a report from core. J Ect 2001;17:244-53.

2 Green SM, Andolfatto G, Krauss B. Ketofol for procedural sedation? pro and con. Ann Emerg Med 2011;57:444-8.

3 Hooten WM, Rasmussen KG. Effects of general anesthetic agents in adults receiving electroconvulsive therapy: a systematic review. J Ect 2008;24:208-23.

4 McGirr A, Berlim MT, Bond DJ, et al. A systematic review and meta-analysis of randomized, double-blind, placebo-controlled trials of ketamine in the rapid treatment of major depressive episodes. Psychol Med 2015;45:693-704.

5 Zheng W, Zhou Y-L, Liu W-J, et al. Investigation of medical effect of multiple ketamine infusions on patients with major depressive disorder. J Psychopharmacol 2019;33:494-501.

6 Strayer RJ, Nelson LS. Adverse events associated with ketamine for procedural sedation in adults. Am J Emerg Med 2008;26:985-1028.

7 Parsaik AK, Singh B, Khosh-Chashm D, et al. Efficacy of ketamine in bipolar depression: systematic review and meta-analysis. J Psychiatr Pract 2015;21:427-35.

8 Han Y, Chen J, Zou D, et al. Efficacy of ketamine in the rapid treatment of major depressive disorder: a meta-analysis of randomized, double-blind, placebo-controlled studies. Neuropsychiatr Dis Treat 2016;12:2859-67.

9 Kishimoto T, Chawla JM, Hagi K, et al. Single-Dose infusion ketamine and non-ketamine $\mathrm{N}$-methyl-D-aspartate receptor antagonists for unipolar and bipolar depression: a meta-analysis of efficacy, safety and time trajectories. Psychol Med 2016;46:1459-72.

$10 \mathrm{Xu}$ Y, Hackett M, Carter G, et al. Effects of low-dose and very low-dose ketamine among patients with major depression: a systematic review and meta-analysis. Int J Neuropsychopharmacol 2016;19:pyv124.

11 Wilkinson ST, Ballard ED, Bloch $\mathrm{MH}$, et al. The effect of a single dose of intravenous ketamine on suicidal ideation: a systematic review and individual participant data meta-analysis. Am J Psychiatry 2018;175:150-8

12 Yalcin S, Aydoğan H, Selek S, et al. Ketofol in electroconvulsive therapy anesthesia: two stones for one bird. J Anesth 2012;26:562-7.

13 Finnegan M, Galligan T, Ryan K, et al. Ketamine versus midazolam for depression relapse prevention following successful electroconvulsive therapy: a randomized controlled pilot trial. J Ect 2019;35:115-21.

14 Rasmussen KG, Jarvis MR, Zorumski CF. Ketamine anesthesia in electroconvulsive therapy. Convuls Ther 1996;12:217-23.

15 Patel AS, Gorst-Unsworth C, Venn RM, et al. Anesthesia and electroconvulsive therapy: a retrospective study comparing etomidate and propofol. J Ect 2006;22:179-83.

16 Mitchell P, Torda T, Hickie I, et al. Propofol as an anaesthetic agent for ECT: effect on outcome and length of course. Aust $N Z \mathrm{~J}$ Psychiatry 1991;25:255-61.

17 Wang X, Chen Y, Zhou X, et al. Effects of propofol and ketamine as combined anesthesia for electroconvulsive therapy in patients with depressive disorder. J Ect 2012;28:128-32.

$18 \mathrm{XM}$ X, JB H, Chen $\mathrm{Y}$, et al. Effects of propofol and ketamine administration in electroconvulsive therapy for patients with major depressive disorder (in Chinese). China health care \& nutrition 2013;23:7597-8

19 Zhao HZ, Li H, Cui EL. A comparative study of intraocular pressure and depression reducing score in depression patients undergoing MECT with different anesthetics (in Chinese). Chinese Journal of Practical Medicine 2016;43:61-3.

20 Zheng W, Li X-H, Zhu X-M, et al. Adjunctive ketamine and electroconvulsive therapy for major depressive disorder: a meta-analysis of randomized controlled trials. J Affect Disord 2019;250:123-31.

21 Ren L, Deng J, Min S, et al. Ketamine in electroconvulsive therapy for depressive disorder: a systematic review and meta-analysis. $J$ Psychiatr Res 2018;104:144-56.

22 Moher D, Liberati A, Tetzlaff J, et al. Preferred reporting items for systematic reviews and meta-analyses: the PRISMA statement.. In: BMJ (Clinical research ed). , 2009: 339, b2535.

23 Zheng W, Cai D-B, Yang X-H, et al. Adjunctive aripiprazole for antipsychotic-related hyperprolactinaemia in patients with first-episode schizophrenia: a meta-analysis. Gen Psychiatr 2019;32:e100091.

24 Zheng W, Zhu X-M, Zhang Q-E, et al. Adjunctive minocycline for major mental disorders: a systematic review. J Psychopharmacol 2019;33:1215-26.

25 McGirr A, Berlim MT, Bond DJ, et al. A systematic review and metaanalysis of randomized controlled trials of adjunctive ketamine in electroconvulsive therapy: efficacy and tolerability. J Psychiatr Res 2015;62:23-30.

26 Fond G, Bennabi D, Haffen E, et al. A Bayesian framework systematic review and meta-analysis of anesthetic agents effectiveness/tolerability profile in electroconvulsive therapy for major depression. Sci Rep 2016;6:19847.

27 Li D-J, Wang F-C, Chu C-S, et al. Significant treatment effect of add-on ketamine anesthesia in electroconvulsive therapy in depressive patients: a meta-analysis. Eur Neuropsychopharmacol 2017;27:29-41.

28 McGirr A, Berlim MT, Bond DJ, et al. Adjunctive ketamine in electroconvulsive therapy: updated systematic review and metaanalysis. Br J Psychiatry 2017;210:403-7.

29 Montgomery SA, Asberg M. A new depression scale designed to be sensitive to change. Br J Psychiatry 1979;134:382-9.

30 Zhong BL, Wang Y, Chen $\mathrm{HH}$, et al. Reliability, validity and sensitivity of Montgomery-Åsberg Depression Rating Scale for patients with current major depressive disorder [in Chinese]. Chinese Journal of Behavioural Medicine and Brain Sciences 2011;20:85-7.

31 Hamilton M. A rating scale for depression. J Neurol Neurosurg Psychiatry 1960;23:56-62.

32 G. R X, Shen QJ. Use of the Chinese version of the Hamilton rating scale for depression in general population and patients with major depression (in Chinese). Chinese Journal of Nervous and Mental Diseases 1984;10:364.

33 Abdallah CG, Fasula M, Kelmendi B, et al. Rapid antidepressant effect of ketamine in the electroconvulsive therapy setting. $J$ Ect 2012;28:157-61.

34 Loo CK, Katalinic N, Garfield JBB, et al. Neuropsychological and mood effects of ketamine in electroconvulsive therapy: a randomised controlled trial. J Affect Disord 2012;142:233-40.

35 Yoosefi A, Sepehri AS, Kargar M, et al. Comparing effects of ketamine and thiopental administration during electroconvulsive therapy in patients with major depressive disorder: a randomized, double-blind study. J Ect 2014;30:15-21.

36 Erdil F, Begeç Z, Kayhan GE, et al. Effects of sevoflurane or ketamine on the QTC interval during electroconvulsive therapy. J Anesth 2015;29:180-5.

37 Erdil F, Ozgul U, Çolak C, et al. Effect of the addition of ketamine to sevoflurane anesthesia on seizure duration in electroconvulsive therapy. J Ect 2015;31:182-5.

38 Kușçu Özlem Özkan, Karacaer F, Biricik E, et al. Effect of ketamine, thiopental and ketamine-thiopental combination during electroconvulsive therapy for depression. Turk $J$ Anaesthesiol Reanim 2015;43:313-7.

39 Salehi B, Mohammadbeigi A, Kamali AR, et al. Impact comparison of ketamine and sodium thiopental on anesthesia during electroconvulsive therapy in major depression patients with drugresistant; a double-blind randomized clinical trial. Ann Card Anaesth 2015;18:486-90.

40 Shams Alizadeh N, Maroufi A, Nasseri K, et al. Antidepressant effect of combined ketamine and electroconvulsive therapy on patients with major depressive disorder: a randomized trial. Iran J Psychiatry Behav Sci 2015;9:e1578.

41 Rybakowski JK, Bodnar A, Krzywotulski M, et al. Ketamine anesthesia, efficacy of electroconvulsive therapy, and cognitive functions in treatment-resistant depression. J Ect 2016;32:164-8.

42 Zhong $\mathrm{X}, \mathrm{He} \mathrm{H}$, Zhang $\mathrm{C}$, et al. Mood and neuropsychological effects of different doses of ketamine in electroconvulsive therapy for treatment-resistant depression. Available: http://onlinelibrary.wiley. com/o/cochrane/clcentral/articles/791/CN-01158791/frame.html;

43 Anderson IM, Blamire A, Branton T, et al. Ketamine augmentation of electroconvulsive therapy to improve neuropsychological and clinical outcomes in depression (Ketamine-ECT): a multicentre, double- 
blind, randomised, parallel-group, superiority trial. Lancet Psychiatry 2017;4:365-77.

44 Chen Q, Min S, Hao X, et al. Effect of low dose of ketamine on learning memory function in patients undergoing electroconvulsive therapy-a randomized, double-blind, controlled clinical study. J Ect 2017;33:89-95.

45 Fernie G, Currie J, Perrin JS, et al. Ketamine as the anaesthetic for electroconvulsive therapy: the KANECT randomised controlled trial. Br J Psychiatry 2017;210:422-8.

46 Ray-Griffith SL, Eads LA, Han X, et al. A randomized pilot study comparing ketamine and methohexital anesthesia for electroconvulsive therapy in patients with depression. $J$ Ect 2017;33:268-71.

47 Zheng W, Cai D-B, Zheng W, et al. Brexanolone for postpartum depression: a meta-analysis of randomized controlled studies. Psychiatry Res 2019;279:83-9.

48 Furukawa TA, Barbui C, Cipriani A, et al. Imputing missing standard deviations in meta-analyses can provide accurate results. J Clin Epidemiol 2006;59:7-10.

49 Higgins J, Green S. Cochrane Handbook for Systematic Reviews of Interventions Version 5.1.0 [updated March 2011]. The Cochrane Collaboration, 2011. Available: www.cochrane-handbook.org

50 Zheng W, Cai D-B, Li H-Y, et al. Adjunctive Peony-Glycyrrhiza decoction for antipsychotic-induced hyperprolactinaemia: a meta-analysis of randomised controlled trials. Gen Psychiatr 2018;31:e100003.
51 Cohen J. Statistical power analysis for the behavioral sciences. 2nd edn. Hillsdale: Lawrence Erlbaum Associates, 1988.

52 DerSimonian R, Laird N. Meta-Analysis in clinical trials. Control Clin Trials 1986;7:177-88.

53 Higgins JPT, Thompson SG, Deeks JJ, et al. Measuring inconsistency in meta-analyses. BMJ 2003;327:557-60.

54 Egger M, Davey Smith G, Schneider M, et al. Bias in meta-analysis detected by a simple, graphical test. BMJ 1997;315:629-34.

55 Higgins J, Higgins J P. Cochrane Handbook for systematic reviews of interventions. John Wiley \& Sons, 2008.

56 Jadad AR, Moore RA, Carroll D, et al. Assessing the quality of reports of randomized clinical trials: is blinding necessary? Control Clin Trials 1996:17:1-12.

57 Balshem H, Helfand M, Schünemann HJ, et al. Grade guidelines: 3. rating the quality of evidence. J Clin Epidemiol 2011;64:401-6.

58 Atkins D, Best D, Briss PA, et al. Grading quality of evidence and strength of recommendations. BMJ 2004;328:1490.

59 ed) Sterne JAC, Sutton AJ, loannidis JPA, et al. Recommendations for examining and interpreting funnel plot asymmetry in metaanalyses of randomised controlled trials.. In: Bmj (clinical research. , 2011: 343, d4002.

60 Guyatt GH, Oxman AD, Vist GE, et al. Grade: an emerging consensus on rating quality of evidence and strength of recommendations. $B M J$ 2008;336:924-6.

61 Jick H, Kaye JA, Jick SS. Antidepressants and the risk of suicidal behaviors. JAMA 2004;292:338-43.



Xiaomei Li obtained a Bachelor's degree from Chongqing Medical University in 2015 and a Master's degree in psychiatry and mental health from Chongqing Medical University in 2019. Her main research interest includes major depressive disorder. 